\title{
Would adding two left atrial piloted images to a cardiac magnetic resonance protocol enable rapid, accurate calculation of left atrial volume? Use of 320 slice cardiac CT as proof of concept.
}

Nitesh Nerlerkar, Stuart Moir

From 19th Annual SCMR Scientific Sessions

Los Angeles, CA, USA. 27-30 January 2016

\section{Background}

Left atrial volume (LAV) is an important prognostic predictor in cardiac disease. LAV is not routinely evaluated by cardiac magnetic resonance (CMR) as acquisition of a full volume dataset is time consuming, and previous authors have shown calculation of LAV using the biplane area-length method (BAL) from routinely acquired 4 and 2 chamber views $(4 \mathrm{CV}, 2 \mathrm{CV})$ significantly underestimates true volume. We hypothesized this underestimation was due to standard CMR 4CV and 2CV images (piloted from mid mitral valve to LV apex - LV piloting) foreshortening the atrium, and that additional $4 \mathrm{CV}$ and $2 \mathrm{CV}$ images piloted from mid mitral valve to the mid posterior wall of the left atrium (LA piloting) would enable rapid, accurate calculation of LAV using BAL.

\section{Methods}

We evaluated 3-D datasets from 44 consecutive patients undergoing retrospective 320 slice cardiac computed tomographic studies. True 3-D left atrial volume (gold standard) was calculated at end systole by a blinded observer excluding pulmonary veins and left atrial appendage. A second blinded observer manipulated images to create standard 'CMR' 4 and 2 chamber views piloted from mid mitral valve to LV apex (standard LV piloted) enabling measurement of LAV using BAL. The dataset was then manipulated / 're-piloted' from mid mitral valve to the middle of posterior LA (LA piloted) and LAV was re-measured - see figure.

\section{Results}

As previously shown, LAVI calculated with BAL from LV piloted $4 \mathrm{CV}$ and $2 \mathrm{CV}$ images significantly underestimates true LAV (see table). Mean LAV calculated from LA piloted images was not significantly different from true LA volume and there was a strong correlation between the 2 with narrow confidence intervals.

\section{Conclusions}

Accurate calculation of LAV can be made using BAL method from LA piloted images, and is superior to calculation from standard LV piloted images. Addition of

Table 1

\begin{tabular}{ccccc}
\hline Method & $\begin{array}{c}\text { Mean } \pm \text { SD } \\
(\mathbf{m l})\end{array}$ & $\begin{array}{c}\text { 95\% Confidence } \\
\text { Interval }\end{array}$ & $\begin{array}{c}\text { Correlation to 3D LAV } \\
(\mathbf{r} \text {-value })\end{array}$ & $\begin{array}{c}\text { Mean difference comparison to 3D-LAV (paired } \\
\text { t-test } \mathbf{p} \text { value) }\end{array}$ \\
\hline 3-D LA volume & $82 \pm 24$ & & & $<0.001$ \\
$\begin{array}{c}\text { LV piloted LA } \\
\text { volume }\end{array}$ & $67 \pm 28$ & $(-19,-12)$ & 0.898 & 0.27 \\
$\begin{array}{c}\text { LA piloted LA } \\
\text { volume }\end{array}$ & $81 \pm 27$ & $(-5,1)$ & 0.922 & \\
\hline
\end{tabular}

Monash HEART, Monash Health, Melbourne, VIC, Australia 


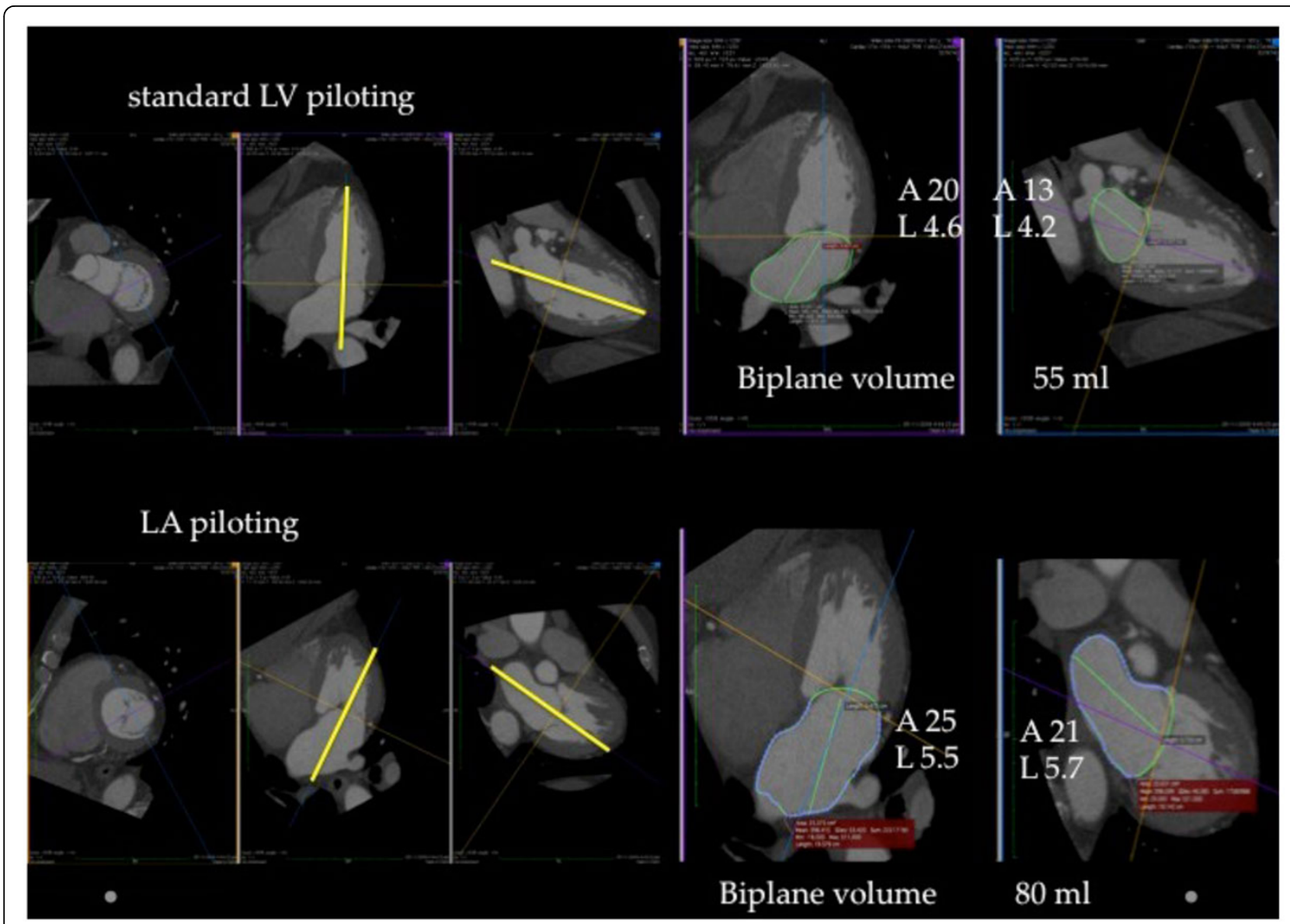

Figure 1

two LA piloted images to a standard CMR protocol may enable rapid and accurate calculation of an important prognostic marker for cardiovascular disease.

Published: 27 January 2016

doi:10.1186/1532-429X-18-S1-Q51

Cite this article as: Nerlerkar and Moir: Would adding two left atrial piloted images to a cardiac magnetic resonance protocol enable rapid, accurate calculation of left atrial volume? Use of 320 slice cardiac CT as proof of concept.. Journal of Cardiovascular Magnetic Resonance 2016 18(Suppl 1):Q51.

\section{Submit your next manuscript to BioMed Central} and take full advantage of:

- Convenient online submission

- Thorough peer review

- No space constraints or color figure charges

- Immediate publication on acceptance

- Inclusion in PubMed, CAS, Scopus and Google Scholar

- Research which is freely available for redistribution 